\title{
Chronic pain acceptance and Social Support Among Patients with Chronic Disease
}

Dr. Ashraf Muwafaq Flaiyah, Ibn Rushd College, University of Baghdad / Iraq Ashraaff2005@yahoo.com

Dr. Saif Mohammed Radeef, Psychological Research Centre, Minstiry of Higher Education \&Scientific Research / Iraq

saifradeef@yahoo.com

Received:29/10/2019

Accepted:16/12/2019

This work is licensed under a Creative Commons Attribution 4.0 International License

\begin{abstract}
Chronic pain acceptance is developing as a vital concept to understand ways that chronic pain patients can remain engaged with valued parts of life. If patients find their pain inacceptable, they will likely work to avoid it at all costs and readily seek to reduce or eliminate it. Such measures may not be of best interest when they require no pain reduction and many missed opportunities to work more effectively and productively.

The purpose of this study was to investigate the level of chronic pain acceptance among individuals who suffering chronic disease as well as to identify the differences in chronic pain acceptance due to gender and age. Furthermore, the study aimed to identify the extent to which social support (family, friends, and government organizations) contribute to predict the acceptance of chronic pain in patients with chronic diseases.

The researchers selected a random sample consisted of (254) ( 1 \& males, 10. females) patients, their age ranged between (20-60) year were participated in this study. Two measurement tools have been used; chronic pain acceptance questioner (CPAQ) and social support scale.

The results showed that females were reported higher level of chronic pain acceptance than male. In addition, the results found a statistically significant positive correlation between a type of social support (family, friends, and government) and acceptance of chronic pain. To measure the contribution of social support sources to the acceptance of pain, the results showed that all sources of social support (family, friends and government) contributed to the acceptance of pain, but the support of friends was the highest contribution to the acceptance of pain.
\end{abstract}

\section{Keywords: Chronic Pain, Social Support, Chronic Disease}




\title{
تقبل الألم المزمن وعلاقته بالمساندة الاجتماعية لدى ذوي الأمر اض المزمنة
}

\author{
م.د.اشرف موفق ا.م.د. سيف محمد رديف
}

جامعة بغداد/كلية التربية ابن رشد وزارة التعليم العالي والبحث العلمي

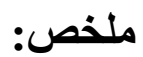

يبرز تقبل الألم المزمن مفهومأ مهماً في فهم الطرق التي يمكن أن يظل بها من يعانون من الألم المزمن مرتبطين بجو انب قيمة من الحياة. عندما يجد المرضى أن آلامهم غبر محتملة ، فمن المحتمل انهم يبذلون

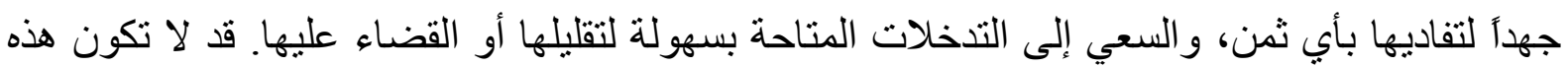
الجهود مثمرة مالم تتضمن النتائج أي انخفاض في الألم.

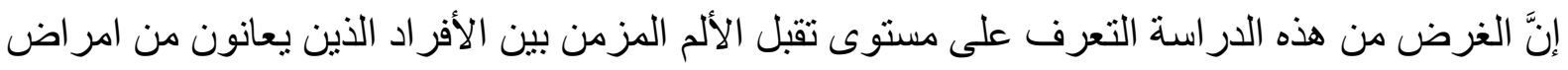

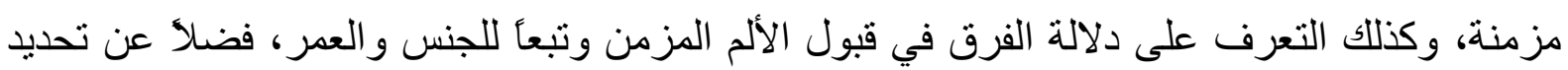

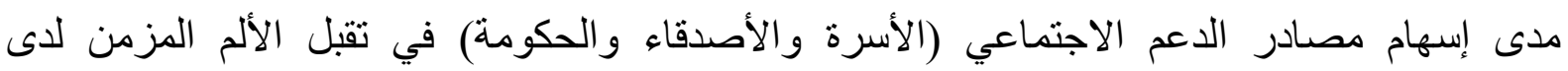
الأشخاص المصابين بأمر اض مزمنة.

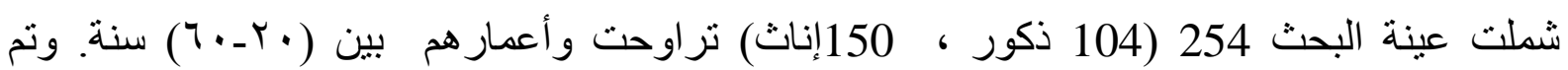
استخدام مقياس تقبل الألم المزمن ، ومقياس الدعم الاجتماعي. وأظهرت نتائج الدراسة أنَّ الإناث قد

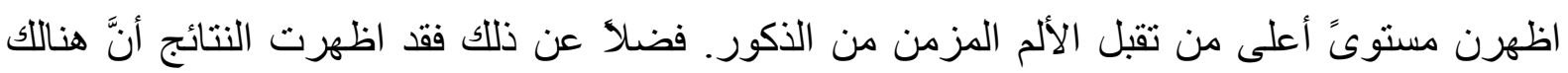

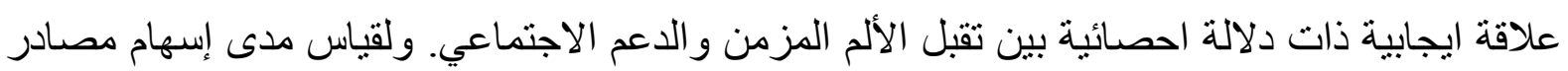

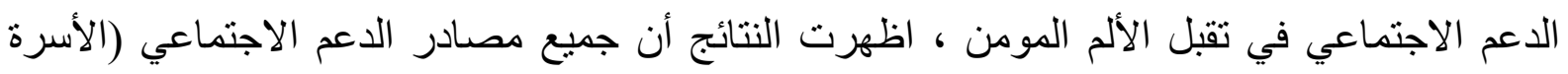
و الأصدقاء والحكومة) قد اسهوت في تقبل الألم ولكن كان دعم الاصدقاء قد شكل المساهمة الاعلى في

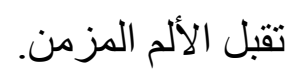
الكلمات المفتاحية: تقبل الالم ، المساندة الاجتماعية ، الامراض المزمنة 


\section{Introduction and Theoretical Background:}

The behavior of patient is now believed to be vital in the development and maintenance of chronic pain and pain related disability. Early understandings of this idea focused mainly on overt 'pain behavior' and its environmental contingencies (Fordyce, 1977).

In the last decade ' acceptance' was found to be an important building for psychotherapies in contexts or the third wave. Though mistaken as surrender often (Turk, 1990). This idea is far from the real concept.

Accepting chronic pain means trying to reduce inability to stop or manage pain and instead concentrating on involvement in enjoyable activities and achieving personal goals (Hayes \& Slrosahl, 2004).

Patients with chronic pain are responding to pain and lead them to be away from healthy life functions. They will assess their pain in stressful ways in which and take these evaluations to be real. Together, they may consider different pain and feelings as strong reasons to breaking away from the necessary valuable aspects for their lives, and they usually act to manage or avoid painful experiences, while producing these behaviors have no positive effect.

Over the last 30 years, dealing with pain came to be the main focus of many studies investigated by pain scholars about patient behavior.

The awareness of coping has immediate appeal and enjoys widespread acceptance by clinicians and clinical researchers. It has supposedly contributed to treatments that produce clear benefits (Morley, Eccleston, \& Williams, 1999). The expression of coping is also readily adopted by patients. However, the common use of the idea of coping in chronic pain study has presented a number of conceptual and empirical difficulties.

It was agreed that the term of coping has at least two phases. The first phase is the definition of coping includes behavior exhibited in response to pain 
regardless of the result and the second phase includes only behavior that successfully reduces the impact of pain.

Often both forms of the concept can operate unchallenged within the same discussion, leading to potential confusion. Following Lazarus and Folkman (1984), coping is usually defined as the effortful (i.e. non-automatic) attempt to adapt to pain, or manage one's own negative response to pain (Jensen, Turner, Romano, \& Karoly, 1991; Keefe, Salley, \& Lefebvre, 1992; Tunks \& Bellissimo, 1988).

The empirical is considered to be the second part of concern for coping. So far, researches of coping with chronic pain have yet to explain that kind of coping responses among the list of many are commonly helpful (Jensen et al., 1991).

Though the success of any specific coping strategy depends upon its behavioral context we are unable to look back across around twenty years of published studies and end with any certainty which coping strategies are probable to promote health and functioning.

Coping researches with pain have lean towards to contradict their implied promise. Most findings tend to concentrate on behaviors, the chronic or persistent use of which, patients could do well to avoid.

This kind of behavior form has been recognized as the source of important human suffering in the regular life experiences (Hayes, Strosahl, \& Wilson, 1999).

Based on this background, it has been argued for adoption of a contextual acceptance based approach to chronic pain, and that approach aims to reduce inflexible behavior patterns that fail the pain patients (L. McCracken, Carson, Eccleston, \& Keefe, 2004; L. McCracken, Eccleston, \& Bell, 2005).

Acceptance of chronic pain requires the strong will to endure discomfort and related emotions when, in particular, this contributes to a more active 
participation in appreciated activities and the accomplishment of personal goals.(L. McCracken et al., 2004).

Acceptance includes responds to pain related experience, especially if these attempts limit quality of life of the patient and engaged in activities regardless of these experiences, without work on control or preventing.

There are at least seven cross-sectional acceptance studies and patients functions in chronic pain patients (Evers et al., 2001; L. McCracken, 1998; L. McCracken \& Eccleston, 2003; L. M. McCracken, Spertus, Janeck, Sinclair, \& Wetzel, 1999; Viane et al., 2003). The consistent message of the study is that greater acknowledgement of c hronic pain involves better emotional, physical, and social functioning, less health care, me dicines and a better work

status through three different acceptance measures in three different countries. Experiencing of persistent pain may cause a search for understanding that primarily focuses on diagnosis and treatment recommendations that will reduce the pain. When initially attempts are failed, patients often undertake a dynamic search to find a therapy (L. McCracken, 1998).In addition, it can be direct the individual's life, leading him to try a diversity of pharmacological, physical and 'alternative' therapies (Candib, 2004).

Although, the pain experience continues, however, patients are challenged with the reality of 'learning to live with' chronic pain (L. McCracken, Ilyse, Amy, Donald, \& F.Todd, 1999).

Literature review has been highlighted that acceptance is a valuable construct to understand adjustment. Using correlational designs, researchers confirmed that acceptance is related with better physical, social and emotional functioning ( $\mathrm{L}$. McCracken, 1998; L. McCracken \& Eccleston, 2003; Viane et al., 2003). Moreover, researchers in clinical studies (Geiser, 1992; L. McCracken, 1998; L. 
McCracken \& Eccleston, 2006; L. McCracken et al., 2005), have verified that increased acceptance is linked with improvements in physical, social and emotional functioning, in work-related functioning, and in pain-relieving and health care use.

It was confirmed that acceptance has many benefits; relatively little is recognized about how patients typically reach at a state of acceptance when they do not experience a formal acceptance-and commitment-based therapy (ACT) program. Several investigation have examined the general process of adjustment (Gullacksen \& Lidbeck, 2004; Schaefer, 1995) and investigators are defined how ACT can encourage acceptance (Hayes, Bissett, et al., 1999; Hayes \& Slrosahl, 2004), according to our best knowledge, no study has examined the meaning or process of pain acceptance outside of therapy.

Similarly, Risdon and others (2003) acknowledged eight accounts of the meaning of acceptance among a group of 30 participants from the community (female were the majority and the average age was 46 years, but no descriptive data about the sample characteristics were provided). The eight accounts are [taking control, living day-to-day, acknowledging limitations, empowerment, accepting loss of self, acknowledging that there is more to life than pain, relinquishing the fight against battle that cannot be won and depended on spiritual power]. Though, just five participants recognized themselves as having chronic pain. It is important to explore the process of acceptance outside of therapy because the vast majority of persons with chronic pain never participate in formalized psychotherapy.

Based on the previous studies, people who experienced chronic pain can showed an acceptance. Therefore, it is likely to find such evidences in an Iraq population.

\section{Aims of study}

The study aimed to: 
1- Identify the level of chronic pain acceptance among individuals who suffering chronic disease.

2- Examine the differences in chronic pain acceptance according to gender and age.

3- Identify the ability to which social support (family, friends, and government) contribute to predict the acceptance of chronic pain in patients with chronic diseases.

\section{Participants}

Two hundred and fifty four (104 males, 150 females) and their age ranged (2060) year Table (1) were chosen selectively from five governmental clinics in Baghdad city. The patients were asked to answer the PaperBased questionnaires.

Table 1: Sample characteristics

\begin{tabular}{cccc}
\hline Variable & Categories & $\mathrm{n}$ & $\%$ \\
\hline \multirow{2}{*}{ gender } & Male & 104 & 40.94 \\
& Female & 150 & 59.05 \\
\hline \multirow{3}{*}{ Age } & $18-28$ & 44 & 17.32 \\
& $29-39$ & 52 & 20.47 \\
& $40-50$ & 90 & 35.43 \\
total & $51-60$ & 68 & 26.77 \\
\hline
\end{tabular}

\section{Inclusion Criteria}

- Individuals aged between 20 and 60years.

- The participants must have at least one chronic disease.

\section{Measurement Tools}

\section{1- The Chronic Pain Acceptance Questionnaire CPAQ}

The Chronic Pain Acceptance Questionnaire CPAQ-revised by (L. McCracken et al., 2004) was used in this study. The 20- item was designed to measure pain acceptance. Two factors identified in the CPAQ-Revised include the scale: Activity engagement (pursuit of life activities regardless of pain). 
Items - 1, 2, 3, 5, 6, 8, 9, 10, 12, 15, 19.

1- Pain willingness (recognition that avoidance and control are often unworkable methods of adapting to chronic pain).

$$
\text { Items - 4, 7, 11, 13, 14, 16, 17, 18, } 20 .
$$

The items in CPAQ range from 1 (never true) to 5 (still true) on a 5-point scale To score the CPAQ, add the items for Activity engagement and Pain willingness to earn a score for every variable to score the CPAQ. Add the scores for each factor together to obtain the total score. Higher scores show higher acceptance rates.

\section{2- Social Support Scale}

There are many scales that have been used to measure social support. Social support scale developed by Jabber (2012) was used with the current study as it was validated on the Iraqi population as well as it was administered in Arabic language. The scale has 13 items to measure the types of social support (family, friends, and government). A 4-point Likert scale ranging from "very much" to "not at all" was used to rate the items for each one of support sources. The subscales of the scale showed a high internal consistency with $.94, .96$, and .94 for family, friends, and GO-NGO respectively.

\section{Translation of the CPAQ}

Several studies have been conducted using translations of the CPAQ into other languages. In our knowledge, the scale in Arabic version has not been founded. An Iraqi psychologist familiar with the topic of research performed the initial translation of the objects. The first author of this study found the Arabic version to be adequate and back translating was conducted by another psychologist (native English speaker) and was able to explain that the Arabic version represented the same subject-matter as the original version.

Factor Analysis 
The 20 items of the accepting of chorine pain Scale were subjected to principal components analysis (PCA) using SPSS version 22. Prior to performing PCA, the suitability of data for factor analysis was assessed. Inspection of the correlation matrix revealed the presence of many coefficients of .31 and above. The value for Kaiser-Meyer-Oklin was 0.74 and above the recommendation for 0.6 and Barlet's sphericity test were statistically significant $(\mathrm{v} 2=1827.997, \mathrm{df}=$ 190, p\.001), showing that data for an evaluation of the variable showing the spherical matrix of an element in Table 3 were acceptable.

From the table above, principal components analysis revealed the presence of two components: Activity engagement and pain willingness with eigenvalues of 3.51 and 3.06, respectively. These factors explain 33\% of variance, and they were consistent with the screen plot shown in Fig. 1 and explained 17.54 and $15.30 \%$ of the scale variance, respectively. As the component plots of varimax rotation shown in Fig. 1, the variance accounted for each factor and the screen plot analysis was consistent with a two-factor solution. As also shown in Table 3 , each item of scale had a strong factor loading using oblique rotation (ranging from .37 to .66) and varimax rotation (ranging from .34 to .84 ), exceeding the criterion of at least .32 to retain a factor (Tabachnick \& Fidell, 2012).With the exception of item (9) which was founded in many factors, so it was excluded from the scale. The reliability of two subscales; the activity engagement subscale and the pain willingness subscale have met the recommended criteria for internal consistency with Cronbach's alphas of .85 and .86 , respectively. 
Table 3- CPAQ Analysis and Principal Component Factor Analysis with Varimax Rotation

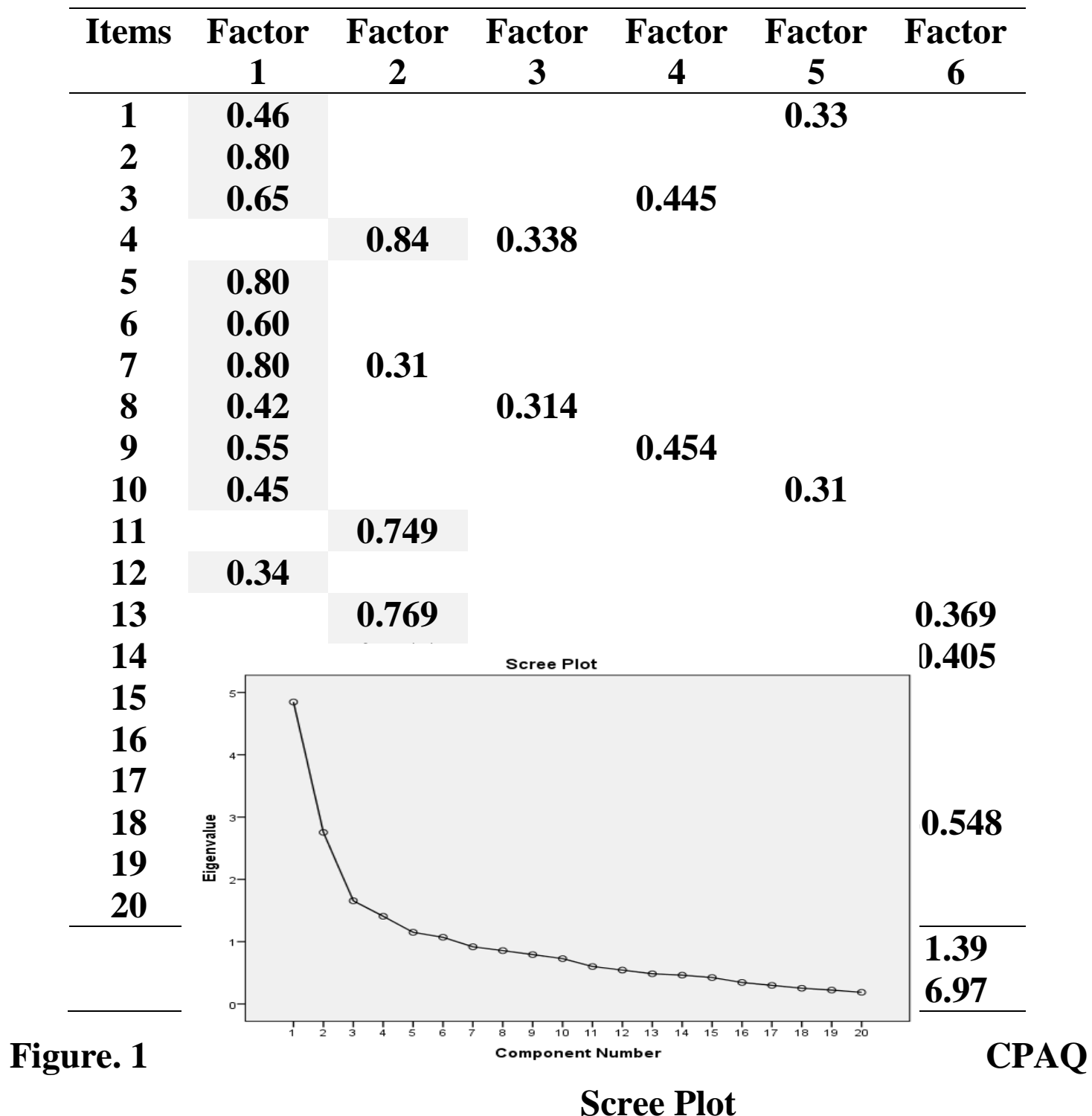

\section{Inter-item correlations}

To measure the Inter-item correlations between the items of the scale, Pearson correlation was used, and the result in Table 4 shows that all items are significantly correlated ( $\mathrm{p} \backslash .01)$ with correlations ranging between .25 and .60 . 
Table 4 Inter-Correlations between Items of CPAQ

\begin{tabular}{cccc}
\hline Items & correlation & Items & correlation \\
\hline $\mathbf{1}$ & 0.38 & $\mathbf{1 1}$ & 0.60 \\
$\mathbf{2}$ & 0.58 & $\mathbf{1 2}$ & 0.37 \\
$\mathbf{3}$ & 0.48 & $\mathbf{1 3}$ & 0.40 \\
$\mathbf{4}$ & 0.49 & $\mathbf{1 4}$ & 0.49 \\
$\mathbf{5}$ & 0.58 & $\mathbf{1 5}$ & 0.59 \\
$\mathbf{6}$ & 0.48 & $\mathbf{1 6}$ & 0.51 \\
$\mathbf{7}$ & 0.55 & $\mathbf{1 7}$ & 0.51 \\
$\mathbf{8}$ & 0.47 & $\mathbf{1 8}$ & 0.25 \\
$\mathbf{9}$ & 0.56 & $\mathbf{1 9}$ & 0.31 \\
$\mathbf{1 0}$ & 0.54 & $\mathbf{2 0}$ & 0.46 \\
\hline
\end{tabular}




\section{Results}

The level of chronic pain acceptance among patients with chronic disease.

In order to achieve the aim of Identify the level of chronic pain acceptance among individuals who suffering chronic disease, a total of 254 individuals were selected as respondents. The mean of chronic pain acceptance was 70.36 \pm 10.10 .

Table 5 showed that female reported higher level of chronic pain acceptance than male $(13.38 \%),(8.66 \%)$ respectively. However, the level of chronic pain acceptance was varying among the categories of age. Individuals who their aged ranged from (40-50) were reported highest level (10.23\%) of chronic pain acceptance among the other groups of age.

Table ( 5 ) Mean and standard deviation of chronic pain acceptance according to gender and age Mean $( \pm \mathrm{SD})$

\begin{tabular}{cccc}
\hline Variable & Categories & Mean (-SD) & Mean (+SD) \\
\hline \multirow{3}{*}{ gender } & Male & $10(4 \%)$ & $22(8.66 \%)$ \\
& Female & $22(8.66 \%)$ & $34(13.38 \%)$ \\
\cline { 2 - 4 } & total & $32(12.60 \%)$ & $56(22.04 \%)$ \\
\hline \multirow{2}{*}{ Age } & $18-28$ & - & $8(3.15 \%)$ \\
& $29-39$ & $8(3.15 \%)$ & $14(5.51 \%)$ \\
& $40-50$ & $14(5.51 \%)$ & $26(10.23 \%)$ \\
& $51-60$ & $10(4 \%)$ & $8(3.15 \%)$ \\
\cline { 2 - 4 } & tota1 & $47(1652 \%)$ & $56(7) \mathrm{n} 4 \%)$
\end{tabular}

\section{Differences in Chronic Pain Acceptance scores according to gender}

In order to achieve this aim, $t$ - test was used to examine the significance differences in chronic pain acceptance according to the gender. Table (5) shows that there are no significant differences between male and female in chronic pain acceptance. 
Table( 5) the Differences in chronic pain acceptance between Males and Females

\begin{tabular}{lcrrrr}
\hline Gender & $\mathbf{N}$ & Mean & Std. Deviation, & $\boldsymbol{t}$ & $\boldsymbol{p}$ \\
\hline Male & 104 & 70.19 & 9.11 & & \\
Female & 150 & 70.48 & 10.76 & .223 & - \\
\hline$* * \mathrm{p}<.01, * \mathrm{p}<.05$ & & & &
\end{tabular}

Differences in Chronic Pain Acceptance scores according to age ANOVA test was used to examine the significance of the differences in chronic pain acceptance according to age. Table (6) shows non- significant difference in chronic pain acceptance scores among the four groups of age.

Table (6) The Differences in chronic pain acceptance according to age

\begin{tabular}{ccccc}
\hline Age & N & Mean & $\begin{array}{c}\text { Std. } \\
\text { Deviation }\end{array}$ & F \\
\hline $18-28$ & 44 & 70.36 & 7.55 & \\
$29-39$ & 52 & 71.73 & 9.34 & .554 \\
$40-50$ & 90 & 70.35 & 11.72 & \\
$51-60$ & 68 & 69.32 & 9.86 & \\
\hline$* *^{2}<.01$ & & & &
\end{tabular}

Identify the ability to which social support (family, friends, and government) contribute to predict the acceptance of chronic pain in people with chronic diseases.

To achieve this aim, Pearson correlation coefficient was obtained between the total scores obtained by the research sample on social support scales (family, friends, and government) and their scores on a scale that chronic pain acceptance table (6).

Table (7) Bivariate correlation in chronic pain acceptance to Social support

Dependent variables Family support Friend support Governmental support 


\footnotetext{
Chronic pain acceptance

.162

.194

.151

The above table shows that there is a statistically significant positive correlation between a type of social support (family, friends, and government) and acceptance of chronic pain by comparing the correlation values above with the value of Pearson coefficient of 0.12 at (0.05).

To determine the extent to which each type of social support contributed to predict the acceptance of chronic pain, a multiple regression analysis was performed. Table (8)
}

Table (8) Regression Variance Analysis of the Contribution of Social Support (Family, Friends, Government) in predicting Chronic Pain Accepting

\begin{tabular}{lccccc}
\hline Source .of.v & $\begin{array}{c}\text { Sum of } \\
\text { Squares }\end{array}$ & df & $\begin{array}{c}\text { Mean } \\
\text { Square }\end{array}$ & f & Sig. \\
\hline Regression & 1665.083 & 3 & 555.028 & & \\
Residual & 24173.594 & 250 & 96.694 & 5.74 & 0.001 \\
Total & 25838.677 & 253 & & &
\end{tabular}

The above table shows that the types of social support (family, friends, and government) contribute to the chronic pain acceptance, as the computed value of the regression analysis variance (5.74), which is higher than the $f$ value of 2.60 at the level (0.05).

To identify the relative contribution of each type of social support (family, friends, government) in the chronic pain acceptance an extracted (Beta) was used table (9). 
Table (9) Standard Beta coefficient of relative contribution and statistical significance

\begin{tabular}{lccccc}
\hline Social Support & $\mathrm{R}$ & $\mathrm{R}^{2}$ & Beta & $\mathrm{t}$ & $\mathrm{p}$ \\
\hline family & & & .15 & 2.154 & .032 \\
friends & .25 & .06 & .22 & 3.166 & .002 \\
government & & & .14 & 2.104 & .036 \\
\hline
\end{tabular}

The above table shows that the types of social support (family, friends, and government) have a statistically significant contribution to the chronic pain acceptance, as the values of the standard Beta coefficient is higher than the calculated t value of (1.96) at the level (0.05) so, the friends support has the highest contribution to the chronic pain acceptance.

\section{Discussion}

The results of the current study show clearly that both male and female reported a high level of chronic pain acceptance. In more details, female showed higher level of chronic pain acceptance than male. The rest of the participants showed a middle level of acceptance.

This finding was inconsistent with previous studie which confirm that females are less acceptable for pain (Ramírez-Maestre \& Esteve, 2014).However, this result was agreed with prior studies that suggest that female could indict a high level of pain acceptance (L. McCracken et al., 2004).

It appears that the female in the study might be better adapted to chronic pain, given their current levels of functioning as she is in charge too many duties at home or outside and that could distract to focus in the pain. In addition, social support could played an effective role to help female to cope with chronic pain as in our culture, females perceived more social support than female.

According to difference in chronic pain acceptance among age categories, individuals who aged between (40-50) years showed the highest level of chronic 
pain acceptance among others age categories. It can be drawn from this finding that older patients have a tendency to to use a broader range of strategies than younger patients do. In addition, this age group is not an elderly and so they may have a lower rate of frustration because they still enjoy life unlike the elderly who may become frustrated and thus accept little pain compared to the age group (40-50) year.

Essentially, older people appear to use a cluster of social support consistently regardless of overall pain intensity. This is consistent with some recent work demonstrating that most aspects of the stress and coping process in older adults are comparable for different stressors across life domains (Moos, Brennan, Schutte, \& Moos, 2006).

It also can be seen from the result that there was a statistically significant positive correlation between a sources of social support (family, friends, and government) and acceptance of chronic pain. In more details, it was founded that friends support was more contribute to the chronic pain.

\section{Conclusion}

According to this result, it is believed that the contribution of friends as a source of social support, which was more than other sources of social support is a logical result because friends are considers in Eastern societies to have a principle roles in individual's life and therefore the patients asking help from them to alleviate chronic pain as well as the poor role of Government organizations in Iraq to provide the necessary social support for patient. 


\section{References}

Candib, L. M. (2004). Making Sense of My Thumbs: Coming to Terms With Chronic Illness. Families, Systems, \& Health, 22(2), 139-151. doi:10.1037/1091-7527.22.2.139

Evers, A. W., Kraaimaat, F. W., van Lankveld, W., Jongen, P. J., Jacobs, J. W., \& Bijlsma, J. W. (2001). Beyond unfavorable thinking: the illness cognition questionnaire for chronic diseases. J Consult Clin Psychol, 69(6), 10261036.

Fordyce, W. E. (1977). Behavioral Methods for Chronic Pain and Illness: St. Louis, Mo.

Geiser, D. (1992). A comparison of acceptance-focused and control-focused interventions in a chronic pain treatment center. .

Gullacksen, A. C., \& Lidbeck, J. (2004). The life adjustment process in chronic pain: psychosocial assessment and clinical implications. Pain Res Manag, 9(3), 145-153. doi:10.1155/2004/373479

Hayes, S., Bissett, R. T., Korn, Z., Zettle, R., Rosenfarb, I., Cooper, L., \& Grundt, A. M. (1999). The impact of acceptance versus control rationales on pain tolerance. Psychological Record, 49, 33-47.

Hayes, S., \& Slrosahl, K. (2004). A Practical Guide to Acceptance and Commitment Therapy.

Hayes, S., Strosahl, K. D., \& Wilson, K. G. (1999). Acceptance and commitment therapy: An experiential approach to behavior change. New York, NY, US: Guilford Press.

Jaber, S. S. (2012). A Self-Help Guide For Traumatised University Students In Iraq. Nottingham university. 
Jensen, M. P., Turner, J. A., Romano, J. M., \& Karoly, P. (1991). Coping with chronic pain: a critical review of the literature. Pain, 47(3), 249-283. doi:10.1016/0304-3959(91)90216-k

Keefe, F. J., Salley, A. N., \& Lefebvre, J. C. (1992). Coping with pain: Conceptual concerns and future directions. Pain, 51(2), 131-134. doi:10.1016/03043959(92)90253-8

Lazarus, R. S., \& Folkman, S. (1984). Stress, appraisal, and coping. New York: Springier.

McCracken, L. (1998). Learning to live with the pain: Acceptance of pain predicts adjustment in persons with chronic pain. Pain, 74, 21-27. doi:10.1016/S0304-3959(97)00146-2

McCracken, L., Carson, J., Eccleston, C., \& Keefe, F. (2004). Acceptance and change in the context of chronic pain. Pain, 109, 4-7. doi:10.1016/j.pain.2004.02.006

McCracken, L., \& Eccleston, C. (2003). Coping or acceptance: What to do about chronic pain? Pain, 105, 197-204. doi:10.1016/S0304-3959(03)00202-1

McCracken, L., \& Eccleston, C. (2006). A comparison of the relative utility of coping and acceptance-based measures in a sample of chronic pain sufferers. Eur J Pain, 10(1), 23-29. doi:10.1016/j.ejpain.2005.01.004

McCracken, L., Eccleston, C., \& Bell, L. (2005). Clinical assessment of behavioral coping responses: Preliminary results from a brief inventory. European journal of pain (London, England), 9, 69-78. doi:10.1016/j.ejpain.2004.04.005

McCracken, L., Ilyse, L., Amy, S., Donald, S., \& F.Todd, W. (1999). Behavioral dimensions of adjustment in persons with chronic pain: pain-related 
anxiety and acceptance. Pain, 80(1-2), 283-289. doi:10.1016/s03043959(98)00219-x

McCracken, L. M., Spertus, I. L., Janeck, A. S., Sinclair, D., \& Wetzel, F. T. (1999). Behavioral dimensions of adjustment in persons with chronic pain: painrelated anxiety and acceptance. Pain, 80(1-2), 283-289. doi:10.1016/s0304-3959(98)00219-x

Moos, R. H., Brennan, P. L., Schutte, K. K., \& Moos, B. S. (2006). Older adults' coping with negative life events: common processes of managing health, interpersonal, and financial/work stressors. International journal of aging \& human development, 62(1), 39-59. doi:10.2190/ENLH-WAA2AX8J-WRT1

Morley, S., Eccleston, C., \& Williams, A. (1999). Systematic review and metaanalysis of randomized controlled trials of cognitive behaviour therapy and behaviour therapy for chronic pain in adults, excluding headache. Pain, 80, 1-13. doi:10.1016/S0304-3959(98)00255-3

Ramírez-Maestre, C., \& Esteve, R. (2014). The Role of Sex/Gender in the Experience of Pain: Resilience, Fear, and Acceptance as Central Variables in the Adjustment of Men and Women With Chronic Pain. The Journal of Pain, 15. doi:10.1016/j.jpain.2014.02.006

Risdon, A., Eccleston, C., Crombez, G., \& McCracken, L. (2003). How can we learn to live with pain? A Q-methodological analysis of the diverse understandings of acceptance of chronic pain. Soc Sci Med, 56(2), 375386. doi:10.1016/s0277-9536(02)00043-6

Schaefer, K. M. (1995). Struggling to maintain balance: a study of women living with fibromyalgia. Journal of Advanced Nursing, 21(1), 95-102. doi:10.1046/j.1365-2648.1995.21010095.x 
Tabachnick, B. G., \& Fidell, L. S. (2012). Using Multivariate Statistics (6th Edition)

Boston, MA.

Tunks, E., \& Bellissimo, A. (1988). Coping with the coping concept: A brief comment. Pain, 34(2), 171-174. doi:https://doi.org/10.1016/03043959(88)90162-5

Turk, D. C. (1990). Customizing treatment for chronic pain patients: who, what, and why. Clin J Pain, 6(4), 255-270.

Viane, I., Crombez, G., Eccleston, C., Poppe, C., Devulder, J., \& de Corte, W. (2003). Acceptance of pain is an independent predictor of mental wellbeing in patients with chronic pain: Empirical evidence and reappraisal. Pain, 106, 65-72. doi:10.1016/S0304-3959(03)00291-4 